\title{
Investigations into Hybrid Magneto-hydrodynamic (MHD) Antenna
}

\author{
Sunil Bist, Dr. Rajveer Singh Yaduvanshi \\ M.Tech. student, Gautam Buddh Technical University, Lucknow, UP, India \\ bist.sunil@rediffmail.com \\ Ambedkar Institute of Advanced Communication Technologies and Research (AIACTR), Delhi, India \\ yaduvanshirs@yahoo.co.in
}

\begin{abstract}
Dielectric Resonator Antennas (DRAs) have received lots of attention in the last two decades due to several attractive characteristics such as high radiation efficiency, light weight, and low profile. There is also increasing challenges for the design of high bandwidth and multi-bands antennas which can be achieved using MHD Antennas for high speed and reconfigurable applications in wireless communication.

In this work the objective is to design and develop a cylindrical MHD antenna with circular patch and two annular rings. Magneto-hydrodynamics (MHD) Antenna is a Fluid based Antenna in which the fluid resonator provides excellent coupling of RF energy into fluid. Fluid resonator volume, chemical properties, electric field and magnetic fields are the factors of resonant frequency, gain and return loss. The proposed antenna shall be tuned in the wide band of frequency range between 7.9 $-27 \mathrm{GHz}$.

Simulations using HFSS and measurements have been carried out in respect of design prototype for 'Air' and BSTO (Barium Strontium Titanate Oxide) microwave fluid. The findings in this work that the Fluid Resonator based hybrid approach for antenna enhances the bandwidth by a large factor and annular rings with circular patch in proper geometry provides multiband operation. Variation in the volume of the fluid shifts the resonant frequency of the solid structure in the wideband. When magnetic field is applied, significant improvement has been noticed in return loss of the proposed antenna.
\end{abstract}

\section{General Terms}

Dielectric Resonator Antenna, Bandwidth, Circular Patch, Fluid Resonator

\section{Indexing terms}

MHD, Reconfigurability, Wideband, Multiband, Annular Ring.

\section{Academic Discipline And Sub- Disciplines}

Electronics and Communication, Wireless Technology

\section{SUBJECT CLASSIFICATION}

Antenna Systems

\section{COVERAGE}

Satellite services for $\mathrm{Ku}$ and $\mathrm{K}$ Microwave frequency Bands

\section{TYPE (METHOD/APPROACH)}

Measurement using Agilent Vector Network Analyzer (VNA) 5230A; Simulation using Ansoft HFSS

\section{INTRODUCTION}

The word magnetohydrodynamics (MHD) is derived from magneto - meaning magnetic field, hydro meaning liquid, and dynamics meaning movement. The field of MHD was initiated by Hannes Alfvén in 1942 and later in 1970, Ting and King determined that the conducting fluid can oscillates under the influence of electromagnetic field conditions. This conducting fluid can be used as one of the element of antenna at microwave frequencies.

An antenna based on the MHD principle using hybrid approach in which a Dielectric Fluid Resonator in combination with circular patch and annular rings is presented. The feed given to this antenna is a microstrip feed. The fluid resonator was filled with 'Air' and 'BSTO (Barium Strontium Titanate Oxide) microwave fluid'. The molecules of the fluid oscillate and impact ionization takes place due to which electromagnetic field changes. The circular patch helps the fluid to resonate in the cylindrical shaped fluid resonator. The annular rings used around Fluid resonator provide multi-band operation.

Measurement for Resonant frequency, Return Loss and impedance matching using 40GHz Agilent VNA (Vector Network Analyzer) 5230A has been performed. In addition to above parameters simulations using HFSS have been carried out for S11, Radiation Pattern and Gain. Taking benefit from the advantages of DRAs and the antenna symmetry using hybrid approach, the results shows wideband $(7.9-27 \mathrm{GHz})$ with multiband features and shift of resonant frequencies by changing fluid volume for the proposed Antenna Prototype.

\section{ANTENNA CONFIGURATION AND DESIGN}

The design methodology started with the investigations of an optimized UWB antenna reported in [6][8][4]. The literature also surveyed regarding reconfigurability in [1][2][3]. The multiband operations using annular rings and patch has been studied from [5][7]. Fig. 1 shows the proposed antenna structure in which a circular patch with two annular rings with a microstrip feed has been designed as per dimensions indicated in Table 1. The feed is attached to outer annular ring and a hollow cylindrical shaped Propylene Random Copolymer (PPR) pipe was fixed on FR4 glass epoxy substrate onto the circular patch. 
Simulations using HFSS have been performed for S11 for all structures of antenna shown in Table 2. Comparison between experimental and simulated results shown in Table-3 has been listed and found to be close.

For an Annular ring Microstrip Antenna (ARMSA) with inner radius ' $a$ ' and outer radius ' $b$ ' with $b / a=2$; and given values of $n$ and $\varepsilon_{r}$, solving the characteristic equation for $\mathrm{k}_{\mathrm{nm}}$ the resonant frequency can be determined by using eq.-(1).

Annular Ring $f_{n m}=\frac{c x_{n m}}{2 \pi a \sqrt{\varepsilon_{r}}}$

Where $x_{n m}=k_{n m} \cdot a$.

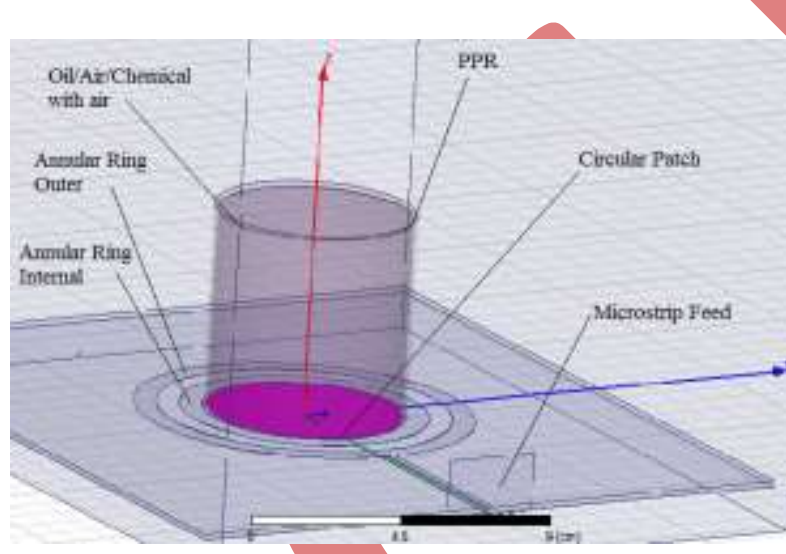

Fig. 1: Proposed Hybrid MHD Antenna (Design-5)
Table 1: Specification of proposed Prototype including intermediate structures

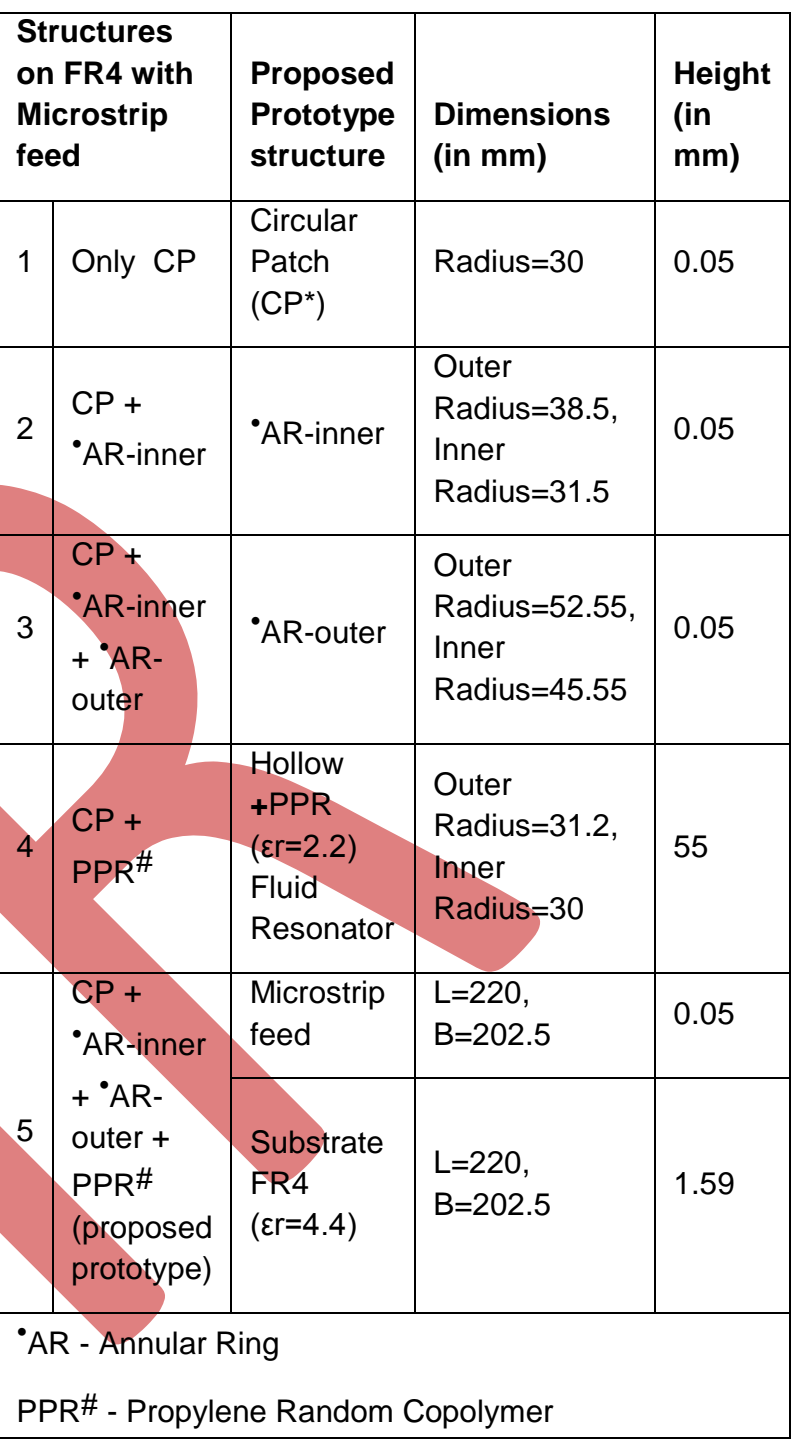

\section{APPROACH TOWARDS THE STRUCTURE OF ANTENNA WITH SIMULATION}

The approach for Hybrid MHD Antenna was started for this work in a phased manner starting from Structure-1 in which a Circular Patch (CP) with a microstrip feed (refer Table-1) and the resonant frequency was found using simulation. The process was repeated for all intermediate structures 2 to proposed prototype 5 (refer Table 1) as well. Fig. 2 shows the layout of structure- 3 while Fig. 3 shows the comparison of simulation results (S11) of structures 1 to 3 .

In order to improve the structure of the antenna for hybrid approach the Fluid Resonator in which the option for Air, Silicone Oil and BSTO, a new structure-4 (dimensions in Table-1) was simulated separately for 'Air', 'Silicone Oil' and 'BSTO' as dielectric in the Fluid Resonator. Comparisons of simulated results are shown in Fig. 4.
The resonant frequency comes to $11.04 \mathrm{GHz}$ for 'Air' using simulations which very close when compared to measured value using VNA as $11.20 \mathrm{GHz}$ at $50 \Omega$. 
Council for Innovative Research www.cirworld.com
International Journal of Computers \& Technology Volume-4, No-2, March- April 2013, ISSN 2277-3061

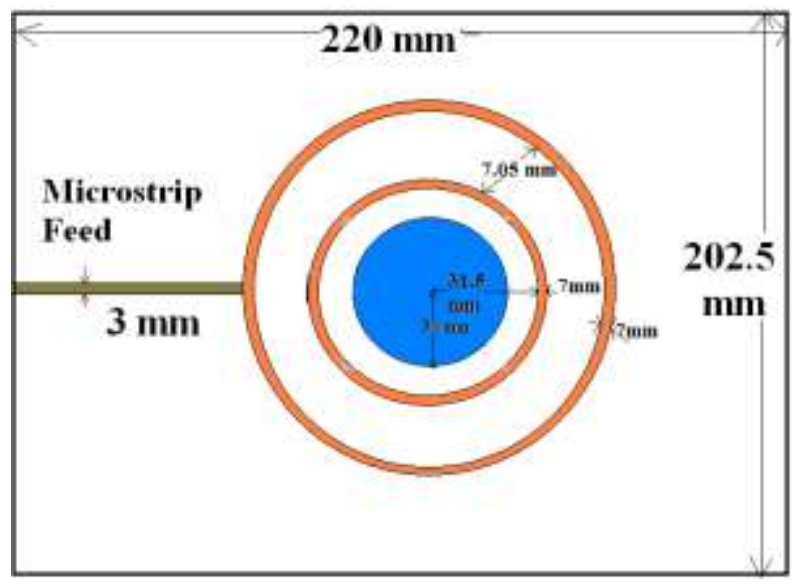

Fig. 2: Layout of Structure-3

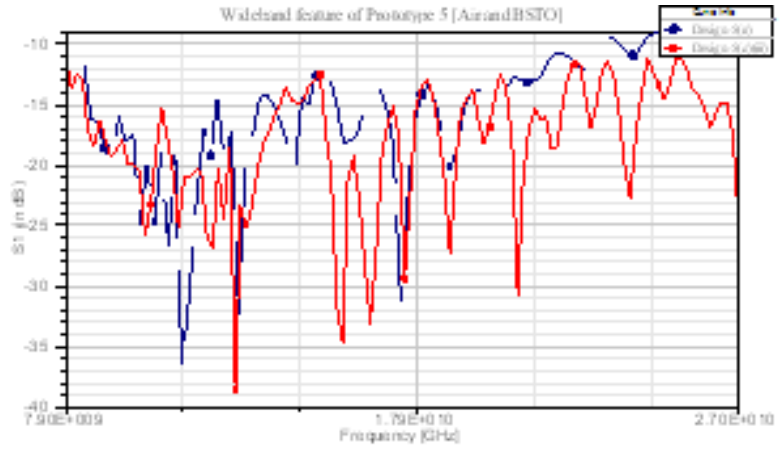

Fig. 5: Wideband for proposed Prototype Measured Vs Simulated for BSTO

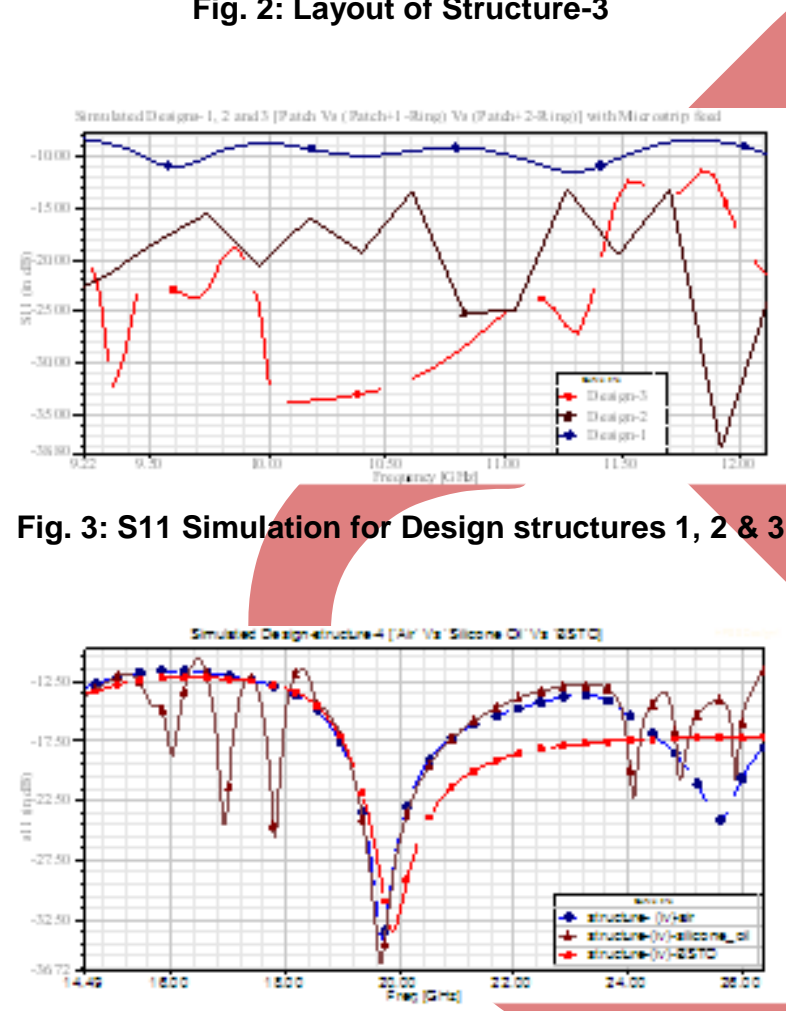

Fig. 4: S11 Simulation for Structure-4 (Air, Silicone Oil and BSTO)

\section{COMPARISON OF DESIGN SIMULATION AND PROTOTYPE MEASUREMENT}

The proposed prototype Design-5 in this work in which the combination of all structures-1, 2, 3 and 4 has been incorporated is shown in Fig. 1 and dimensions shown in Table 1. The simulated results for all structures discussed are shown in Table-2. Structure-4 and proposed prototype-5 have been simulated for 'Air', 'Silicone Oil' and 'BSTO' filled in PPR Fluid Resonator.
Table-2: Simulated Results Summary of all structures upto Design Prototype

\begin{tabular}{|c|c|c|c|c|c|c|c|}
\hline $\begin{array}{l}\text { S. } \\
\text { No }\end{array}$ & \multicolumn{4}{|c|}{ Design Description } & $\begin{array}{l}\text { S11 } \\
(d B)\end{array}$ & $\begin{array}{l}\text { fo } \\
\text { (GHz) }\end{array}$ & $\begin{array}{l}\text { Range } \\
\text { of } \\
\text { Band } \\
\text { (GHz) }\end{array}$ \\
\hline \multicolumn{5}{|c|}{ Circular Patch (CP) } & -11.49 & 11.28 & $\begin{array}{c}11.04 \\
\text { to } \\
11.53\end{array}$ \\
\hline 2 & \multicolumn{4}{|c|}{$\begin{array}{l}\mathrm{CP}+\text { Inner Annular } \\
\text { Ring (AR) }\end{array}$} & -38.27 & 11.92 & $\begin{array}{l}7.4 \text { to } \\
12.79\end{array}$ \\
\hline 3 & \multicolumn{4}{|c|}{$\begin{array}{l}\mathrm{CP}+\text { Inner and Outer } \\
\mathrm{AR}\end{array}$} & -33.79 & 10.01 & $\begin{array}{l}7.4 \text { to } \\
12.98\end{array}$ \\
\hline \multirow{3}{*}{4} & \multirow{3}{*}{\multicolumn{2}{|c|}{$\begin{array}{l}\text { F } \\
\text { I } \\
\text { L } \\
\text { L } \\
\text { E } \\
\text { D }\end{array}$}} & \multicolumn{2}{|c|}{$\begin{array}{l}\text { AIR } \\
(\varepsilon r=1)\end{array}$} & -33.8 & 19.7 & $\begin{array}{r}12.3 \\
\text { to } 27\end{array}$ \\
\hline & & & \multicolumn{2}{|c|}{$\begin{array}{l}\text { Silicone } \\
\text { Oil } \\
(\varepsilon r=2.5)\end{array}$} & -36.1 & 19.6 & $\begin{array}{l}12.3 \\
\text { to } 27\end{array}$ \\
\hline & & & \multicolumn{2}{|c|}{$\begin{array}{l}\text { BSTO } \\
(\varepsilon r=10)\end{array}$} & -33.1 & 19.9 & $\begin{array}{r}11.9 \\
\text { to } 27\end{array}$ \\
\hline \multirow{5}{*}{5} & \multirow{5}{*}{$\begin{array}{c}\text { Design } \\
\text { Proto- } \\
\text { type } \\
(\mathrm{CP}+ \\
\text { Inner } \\
\mathrm{AR}+ \\
\text { Outer } \\
\mathrm{AR}+ \\
\mathrm{PPR})\end{array}$} & \multirow{5}{*}{$\begin{array}{l}\text { V } \\
\text { O } \\
\text { L } \\
\text { U } \\
M \\
E\end{array}$} & \multicolumn{2}{|c|}{$\begin{array}{l}\text { AIR } \\
(\varepsilon r=1)\end{array}$} & -37.4 & 11.0 & $\begin{array}{c}7.83 \\
\text { to } \\
25.74\end{array}$ \\
\hline & & & \multicolumn{2}{|c|}{$\begin{array}{l}\text { Silicone } \\
\text { Oil } \\
(\varepsilon r=2.5)\end{array}$} & -43.8 & 9.36 & $\begin{array}{c}7.87 \\
\text { to } \\
26.83\end{array}$ \\
\hline & & & $\begin{array}{l}B \\
S\end{array}$ & $\begin{array}{l}1 / 3 \\
\text { BS } \\
\text { TO }\end{array}$ & -40 & 9.3 & $\begin{array}{c}7.84 \\
\text { to } \\
24.68\end{array}$ \\
\hline & & & $\begin{array}{l}\mathrm{T} \\
\mathrm{O}\end{array}$ & $\begin{array}{l}2 / 3 \\
\text { BS } \\
\text { TO }\end{array}$ & -33.9 & 13.4 & $\begin{array}{c}7.9 \text { to } \\
27\end{array}$ \\
\hline & & & $\begin{array}{c}(\varepsilon r= \\
10)\end{array}$ & $\begin{array}{l}\text { FU } \\
\text { LL }\end{array}$ & -34.3 & 10.0 & $\begin{array}{c}7.9 \text { to } \\
27\end{array}$ \\
\hline
\end{tabular}


Council for Innovative Research www.cirworld.com
International Journal of Computers \& Technology Volume-4, No-2, March- April 2013, ISSN 2277-3061
The proposed prototype presented as per Structure- 5 was measured using Vector Network Analyzer (VNA) and figures 5 to 9 shows the comparison due to which Wideband, Multiband and Reconfigurability can be seen.

i) Fig. 5 shows the wideband offered

ii) Fig. 6 shows the effect of magnetic field in wideband

iii) Fig. 7 shows the $50.056 \Omega$ impedance at $12.715 \mathrm{GHz}$

iv) Fig. 8 show the multiband produced by annular rings

v) Fig. 9 shows resonant frequency shift by making variation in volume of BSTO

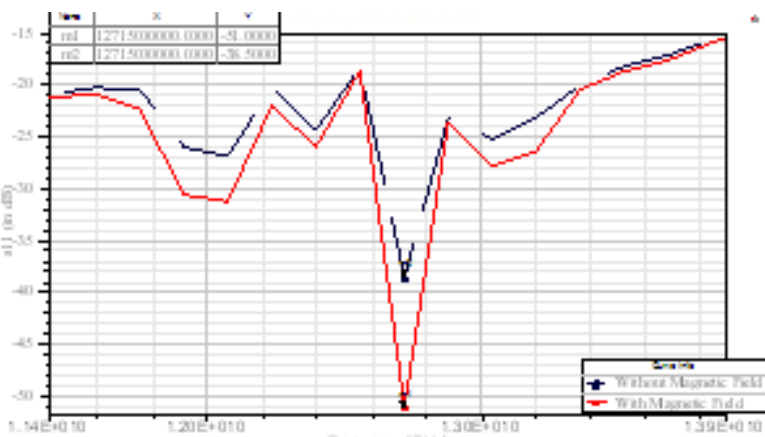

Fig. 6: Measurement of proposed prototype with and without magnetic field.

Fig. 7: Smith Chart - Input Impedance for proposed prototype at $12.715 \mathrm{GHz}$

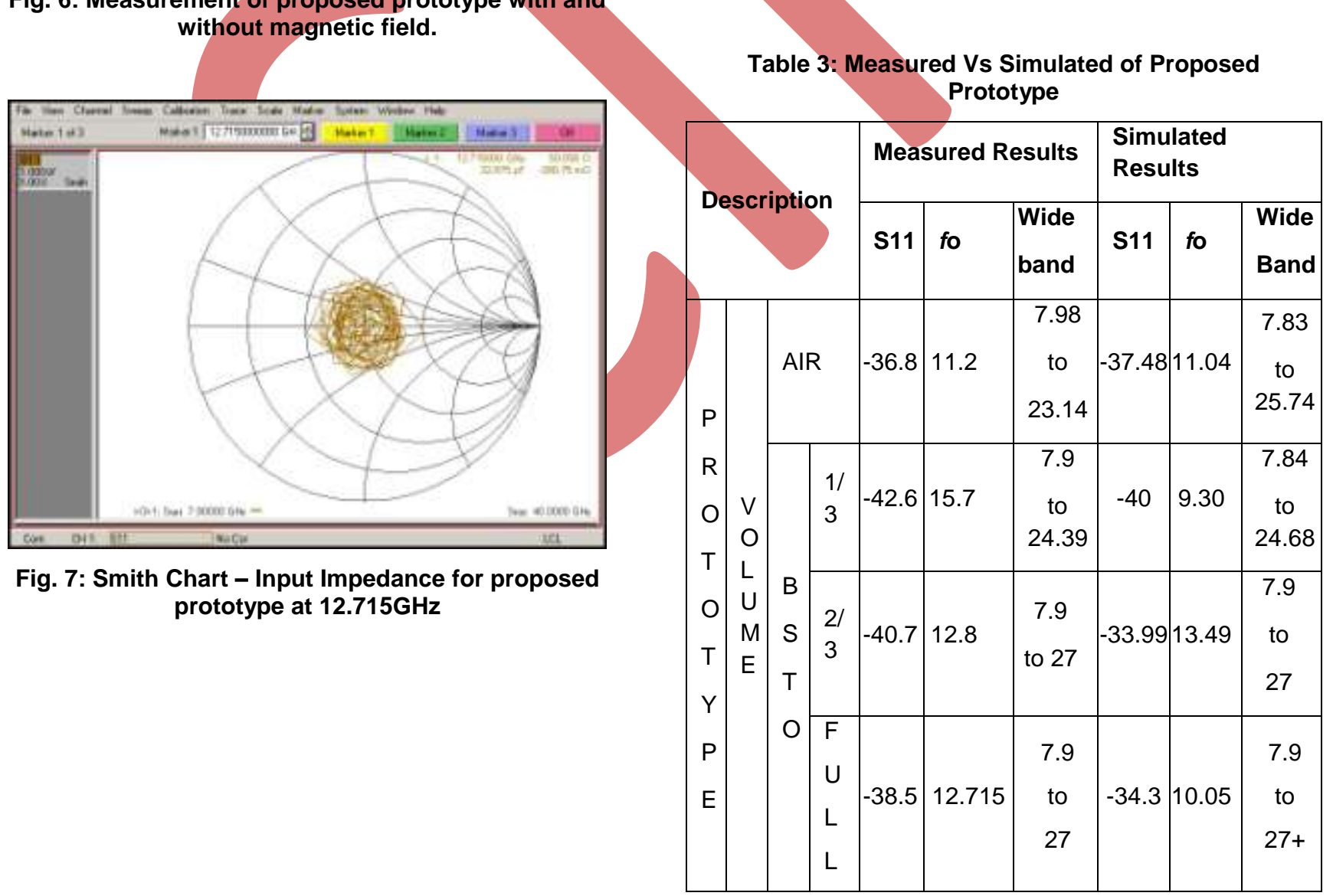

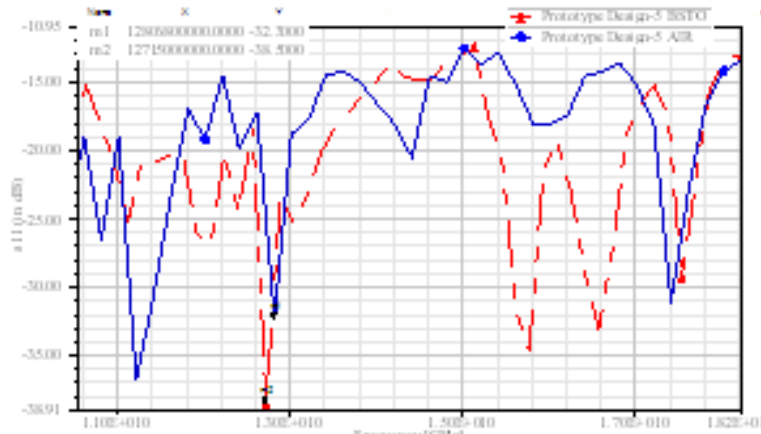

Fig. 8: Effects of Annular Rings in proposed prototype for 'Air' and 'BSTO' 


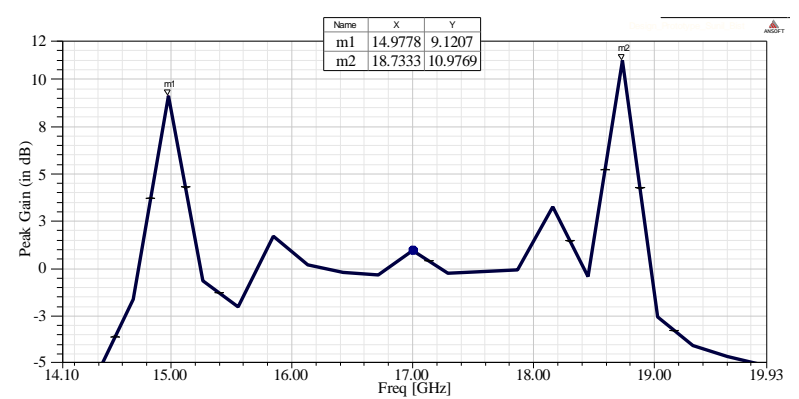

Fig. 10: Rectangular plot of Peak Gain Vs frequency for full BSTO

In addition to above, simulations have been performed for Gain and Radiation pattern as shown in Fig.10 and Fig. 11. Table 3 shows comparison of measured Results (using VNA in AIACTR Research Laboratory) with simulated results using HFSS for S11 (return loss). Magnetic field was also applied and variations in return loss were compared in graphical form.

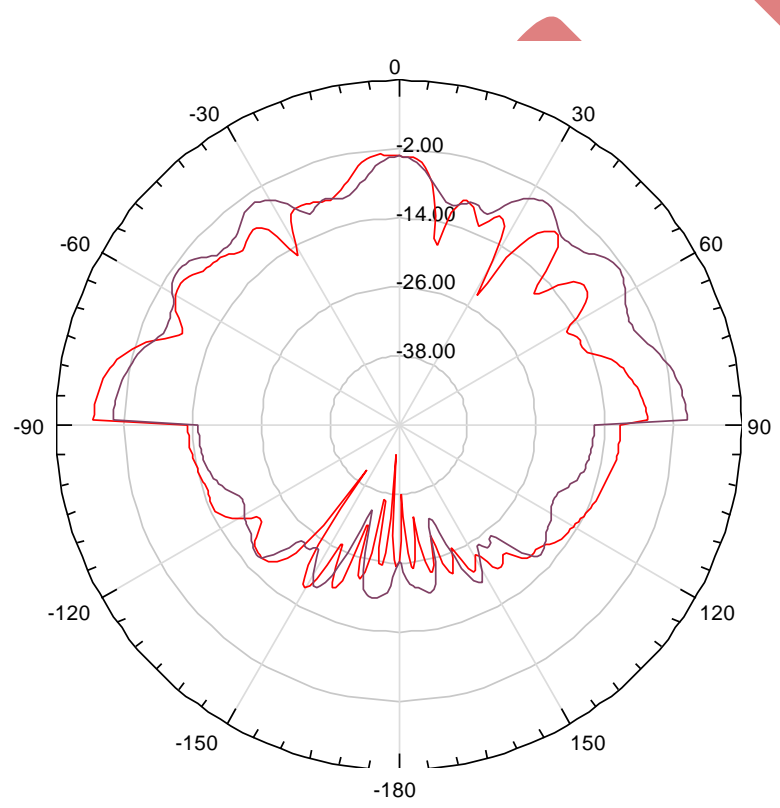

Fig. 11: Radiation Pattern for Design-5 (full BSTO) at $11 \mathrm{GHz}$

\section{CONCLUSION AND DISCUSSION}

The wideband of the proposed Hybrid MHD Antenna measured for 'Air' comes between $7.83 \mathrm{GHz}$ to $25.74 \mathrm{GHz}$ while for BSTO (full in PPR) it is found more as 7.9 to $27 \mathrm{GHz}$ (Table 3 ). Under magnetic field the return loss for proposed prototype (full BSTO) was much reduced at all resonant frequencies under wideband. The input impedance measured using VNA at $12.715 \mathrm{GHz}$ was found as $50.056 \Omega$.

The proposed prototype offers multiband when Annular Rings are included in the proposed design. Multiple resonant frequencies offered by annular rings as shown in measured and simulated results for 'Air' and 'BSTO' filled PPR.

Also, the varying volume of fluid shifts the resonant frequency. The return loss becoming minimum as the volume of the BSTO is increased in PPR. Also the bandwidth increases for an increase in volume of the dielectric fluid (BSTO). It has been seen the ascending order of the wideband as - 'Air' $\rightarrow$ '1/3 BSTO' $\rightarrow$ '2/3 BSTO' $\rightarrow$ 'Full BSTO'.

\section{SCOPE OF FUTURE WORK}

There can be other geometries which can be replaced for fluid resonator like elliptical, octagon, and hexagon for wideband performance analysis as these structures may be specifically suitable for certain applications due to its physical features and special electrical characteristics. Various types of fluids can also be tested with varying volume to achieve the reconfigurability aspect. Possibility of reducing the size of the antenna by meta-material is another interesting area.

\section{ACKNOWLEDGMENTS}

We extend our sincere thanks to the Principal and HOD (Electronics and Communication Engineering), Ambedkar Institute of Advanced Communication Technologies and Research (AIACTR), Government of NCT, Delhi, India for their full support towards the facilities available in Microwave Research.

\section{REFERENCES}

[1] Yaduvanshi, R.S., Parthasarathy, H. and De, A. Magneto-Hydrodynamic Antenna Design and Development Analysis with Prototype. International Journal of Advanced Computer Science and Applications (IJACSA), vol. 2, no.2, pp. 97-104, Feb., 2011.

[2] Fang, X.S., Chow, C.K., Leung, K.W. and Lim, E.H. New Single-/Dual-Mode Design Formulas of the Rectangular Dielectric Resonator Antenna Using Covariance Matrix Adaptation Evolutionary Strategy. Antennas and Wireless Propagation Letters, IEEE, Vol. 10, pp 734-737, 2011.

[3] Petosa, A. and Ittipiboon, A. Dielectric Resonator Antennas: A Historical Review and the Current State of the Art. Antennas and Propagation Magazine, IEEE, vol. 52, issue 5, pp. 91-116, 2010.

[4] Wang, X., Jiao, Y., Weng, Z. and Zhang, F. Slot-fed Cylindrical Dielectric Resonator Antenna (DRA) for Wideband Application. Antennas Propagation and EM Theory (ISAPE), pp. 263-266, 2010 [9th International Symposium, 2010].

[5] Zou, L., Abbott, D. and Fumeaux, C. Omnidirectional Cylindrical Dielectric Resonator Antenna With Dual Polarization. Antennas and Wireless Propagation Letters, IEEE, vol. 11, pp 515-518, 2012.

[6] Xianling, L., Yang, D., Jin, R. and Geng, J. A 60$\mathrm{GHz}$ Wideband Dielectric Resonator Antenna With Inclined Radiation. Antenna Technology (iWAT), IEEE, pp. 124-127, 2012 [International Workshop]. 
[7] Kanaujia, B.K. and Singh, A.K. Analysis and Design of Gap-Coupled Annular Ring Microstrip Antenna. International Journal of Antennas and Propagation, Article ID 792123, 2008.

[8] Lapierre, M., Antar, M.M., Ittipiboon, A. and Petosa, A. A Wideband Monopole Antenna Using Dielectric
Resonator Loading. Antennas and Propagation Society International Symposium, IEEE, vol. 3, pp. 16-19, June, 2003.

\section{Author' biography with Photo}

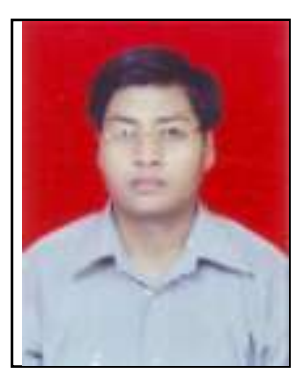

Ist Author's is completing his M.Tech. (Advance Electronics and Communication Engineering) specialization in VLSI Design in 2013 from Gautam Buddh Technical University (formerly Uttar Pradesh Technical University), Lucknow, U.P., India as a Modular student. In addition he is working as an Assistant Professor (ECE Department) in Lingaya's University, Faridabad, Haryana, India.

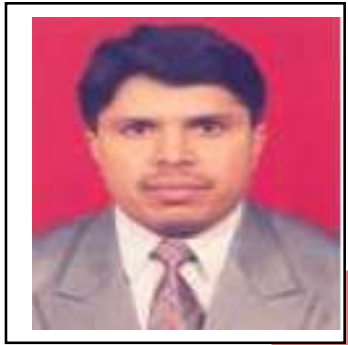

2 nd Author's has 23 years of teaching and research experience. He has successfully implemented fighter aircraft arresting barrier projects at select flying stations of Indian Air Force. He has worked on Indigenization projects of 3D radars at BEL and visited France for Radar Modernisation as Senior Scientific Officer in Min of Defence. Currently he is working on MHD projects. $\mathrm{He}$ is teaching in ECE Department of Ambedkar Institute of Advanced Communication Technologies and Research (AIACTR), Govt. of Delhi, India. $\mathrm{He}$ is fellow member of IETE. His research includes Sixteen number of research papers published in international journals and conferences. 